\title{
A Phenomenological Investigation into the Psychotherapist's Experience of Processing Projective Identifications
}

\author{
Mark Thorpe \\ Senior lecturer, Auckland University of TeCHNology ANd CLINICAL \\ psychologist at Psychotherapy at Apollo, AuCKLAND
}

\begin{abstract}
Projective identification is arguably one of the most important, complex and difficult to understand psychoanalytic concepts. This paper discusses research which aims to develop a phenomenological description of the psychotherapist's experience of identifying, containing and processing the client's projective identifications. The researcher interviewed eight psychoanalytic psychotherapists in depth. The empirical phenomenological method was then used to explicate the transcribed interviews. The results are dialogued with clinical illustrations and the literature on projective identification.
\end{abstract}

\section{Waitara}

Tērā pea kō te whakapūreo tuakiri tētahi o ngā ariā tātarihanga hinengaro whakahirahira, matatini ki te whakamātau. Ko tā tēnei tuhinga, he matapaki i ngā rangahau e whai ana ki te whanake i tētahi whakaahua whakaataata wheako kaitātari hinengaro tohu, pupuri, taki pūreo tuakiri kiritaki. Tokowaru ngā kaitātari whakaora hinengaro i whakamātautau hōhonuhia e te kairangahau, ka whakamahia te huarahi whakamātau whakahirahira ki ngā tuhinga whakamātautau. Ko ngā hua i matapakihia ki te taha o ngā whakaahua haumanu me ngā tuhinga hāngai ki te whakapūreo tuakiri.

Keywords: projective identification; psychoanalytic concepts; processing projections; phenomenological investigation

The term projective identification was first coined by Melanie Klein (1946) and like other psychoanalytic concepts, has subsequently undergone a progressive development (Meissner, 1987; Sandler,1976). The most important advance has been the inclusion of the interpersonal

Thorpe, M. (2016). A phenomenological investigation into the psychotherapist's experience of processing projective identifications. Ata: Journal of Psychotherapy Aotearoa New Zealand, 20(2), 183-197. DOI:10.9791/ ajpanz.2016.16 ( ) New Zealand Association of Psychotherapists Inc. 
dimension, first discussed by Wilfred Bion (1959, 1962). This conceptual expansion has made the recipient, or target of the projection, an integral part of the system of understanding.

Combining the formulations of Sandler (1987), Kernberg (1987) and Ogden (1979,1982), I define projective identification as a group of phantasies based on object relations involving four phases, which together make up a single psychological unit consisting of: 1 ) the client's unconscious phantasy of projecting split off parts, or affects, into the therapist; 2) the client's simultaneous interpersonal pressure on the therapist to play out a role congruent with the phantasy; 3) the therapist's processing of the evoked feelings, and finally; 4) the reintrojection of the projection in modified and less pernicious form by the client through interaction with the therapist.

The focus of this research is on the third phase of projective identification, vis-a-vis the process whereby the therapist contains (Bion, 1962), processes (Ogden, 1982, 2016), or metabolises (Langs, 1982) the client's projective identifications. The aim is to accurately describe the therapist's lived experience of successfully identifying, containing and processing the feelings, thoughts or fantasies evoked by the client's projective identifications. By providing thoroughgoing, experientially oriented research, it is hoped to develop the beginnings of an empirical foundation for the understanding of what constitutes the therapist's experience of this process. The necessity for such a foundation is underscored by Meissner (1987), who stated that "we are struggling with very complex phenomena with a very limited vocabulary with which to express and interpret our experiences" (p. 196). It is hoped that such information, which speaks to the therapist's actual lived experience, could be of practical value to clinicians.

\section{The Need for the Research}

Within psychoanalysis the importance of projective identification as a theoretical construct and practical clinical tool has developed concurrently with the rapid growth of literature on countertransference (Epstein \& Feiner, 1979; Spillius \& O’Shaughnessy, 2012). Ogden (1982) speaks of the growing sense of importance and usefulness of the concept as a means of understanding the therapeutic process, while Bion (1961) views projective identification as the most important form of interaction between client and therapist. Mirroring these views, Rosenfeld (1983) states that "In analytic work today, the analysis of projective identification plays such a prominent part that we can no longer imagine how an analyst could work before 1946" (p. 262).

Langs (1981) points to the therapeutic importance of projective identification when he states that "interactionally, one of the analyst's basic functions is to receive, contain, metabolise and interpret the client's projective identifications” (p. 222). A variety of authors, Adler and Rhine (1988), Grotstein (1981), Langs (1976a), Malin and Grotstein (1966), Ogden $(1982,2016)$ and Searles (1963), have suggested that the essential therapeutic factor is that of the therapist receiving the client's projections, processing them, and then making them available to the client for re-internalisation through the therapeutic interaction.

According to Langs (1976), most studies of projective identification naively assume that the therapist simply, adaptively contains and metabolises the projective identifications leading to interpretive insight. Some notable exceptions to this trend (Bion, 1962; Grinberg, 
1962; Langs, 1976) have shown that the process is not a simple one that occurs automatically, but that countertransference greatly influences the therapist's management of projective identifications and the containing functions. Gold (1983) states that the problem for the therapist is how to recognise, withstand and metabolise the client's projections without recourse to omnipotent psychoanalytic interpretations.

Ogden (1982) writes that the major foci in the literature have been on the unconscious projective phantasy and on the interpersonal pressure involved in projective identification, and suggests that not enough has been written on the phenomenology of the processing of projective identifications. This study is a response to Ogden's appeal to start filling this gap.

\section{Method}

In order to obtain a deeply reflective understanding of the lived experience of processing a projective identification, the methodology of choice was empirical phenomenological as described by Giorgi (1970; 2009), Kruger (1985), Wertz (1983; 1986) and Holloway and Todres (2003). Fifteen long-term, psychoanalytic psychotherapists were interviewed. The audiotaped interviews were transcribed and the eight psychologically richest accounts were chosen for the study.

Each subject was presented with the research question at the beginning of the interview. The interviews ranged from one to two hours in duration. Once the subjects indicated they were finished speaking, the researcher asked questions to clarify areas of uncertainty.

The research question was formulated through closely examining case histories containing descriptions of processing projective identifications. The question was:

During the course of psychotherapy with a specific client, have you as therapist, experienced a thought, feeling, fantasy or manner of relating, which took you some time to come to terms with? If so, please describe your experience of the event as accurately and in as much detail as possible.

\section{Explication of the Data}

The selected transcripts were explicated using the following steps:

- Each protocol was read numerous times to obtain an intuitive grasp of the data.

- The text was then broken into manageable units, termed natural meaning units. These units are discriminations according to changes in meaning, perceived by the researcher when assuming a psychological attitude.

- Through the process of reflection and imaginative variation (Giorgi \& Giorgi, 2008; Wertz, 1986), the researcher re-articulated each of the demarcated meaning units into psychological language, yielding what are called transformed meaning units.

- The transformed meaning units are then regrouped according to their intertwining meanings to accurately reflect the subject's experience over a period of time. The regrouped meaning units were then synthesised and integrated into a consistent description. This is referred to as the situated structure.

- The transformed meaning units were then expressed as central themes, each expressing 
the essence of a number of transformed units.

- The remaining interviews were then read with the aim of unearthing data that could add to the clinical situated structures and central themes already constructed. This information helped clarify and lift out meanings of some of the more obscure themes.

- The situated structures and central themes were read until common themes emerged. From this, an extended description was constructed.

- Finally, the essential structure was constructed. This embodied the necessary and sufficient conditions, constituents and structural relations, which constitute the phenomenon of processing a projective identification.

\section{Results}

Two aspects of the results will now be presented;1) an example of a situated structure, and 2) the essential structure.

\section{Situated structure: Therapist B and the client, Judy}

The situated structure consists of the transformed meaning units, regrouped to reflect accurately the subject's experience over time. The regrouped meaning units are synthesised and integrated into a consistent description. This description reads considerably more coherently than the original transcriptions which were strongly reminiscent of free associations.

Judy struggled to express her feelings. Therapist B found the long silences difficult and experienced a heaviness in the sessions. The therapist began to experience an irresistible sleepiness. The feeling was worse than wanting to fall asleep, it was soporific. She felt drugged the minute she entered the therapy room, and unbelievably heavy and exhausted after the sessions.

Therapist B noticed that moments of real contact were soon spoilt or destroyed by Judy. She thought that nothing she did was of help, and began to feel impotent, helpless, threatened, and uncomfortable. After the session, she found herself becoming angry and over time realised that she was not looking forward to Judy's sessions. She felt she had reached the end of her tether and imagined telling Judy to "fuck off."

Therapist B did not understand what was happening. She felt uncomfortable because she thought her sleepiness was unacceptable and tried to resist it by biting the inside of her cheeks, clenching her fists, or digging her nails into her legs. When the sleepiness became irresistible, the therapist told Judy that if she fell asleep in the session it was because she felt impotent and was withdrawing. Although contraindicated by the literature and her supervisor, the therapist justified her action by saying that the situation would have been more confusing if she had failed to name it.

Although uneasy with the idea of falling asleep, Therapist B decided to give in to the feelings and deal with the consequences later. She felt relieved when she stopped resisting the process and momentarily fell asleep. Judy became furious, which woke them both up. This process continued intermittently for some time. When the therapist later realised her sleepiness was part of the process, she felt less guilty.

Therapist B wondered what was happening to her and found it difficult to put her 
experience into words. Her supervisor was equally confused. The therapist thought her sleepiness was due to the session being in the late afternoon. She later discarded this hypothesis because she was not sleepy in the sessions before or after. She began to explore the idea that Judy needed to control her. After interpreting Judy's fear of contact and need to control, the therapist's sleepiness stopped. However, Judy began to attack her in different ways and the sleepiness returned. The therapist thought that her initial confrontation had exacerbated the situation.

Therapist B gradually thematised her own experience of anger and helplessness. She realised that it was related to; a) the client's fear of her and b) the client's anger with her. She thought that her experience of wanting to get rid of Judy was a reflection of Judy's feelings of fear and anger. She conceptualised the anger as a projective identification which freed Judy from the discomfort of experiencing it. The therapist felt she had experienced Judy's anger in her "guts". She then began to explore Judy's neediness and rage in the therapy.

Therapist B remembered that she had previously had trouble in recognising sadistic attacks in other therapies. Well into this therapy, she recognised a pattern of sadistic attack by Judy and thought it was the cause of her sleepiness. She thought that the control and attack gave Judy a feeling of triumph and excitement, which were defences against the pain of helplessness and dependency. She hypothesised that Judy felt a need to destroy the therapy, because it put her in touch with her feelings of dependency and vulnerability.

Therapist B realised that Judy's method of controlling her was to paralyze her, render her inactive and impotent, but at the same time remain fused with her. She analogously saw herself in a paralyzed state, "like an insect that had been stung and immobilised". She postulated that Judy needed to control her in such a way that she was there, but not asleep.

The therapist was not sure whether her sleepiness was the result of Judy's attack or her own resistance to it, in other words, whether the experience was a projective identification or her own countertransference.

A significant transition occurred when the therapist understood and connected; and c) her own sadistic impulses towards Judy. At this stage, her anger abated and her sleepiness disappeared. She no longer needed to express the feelings she experienced, and was able to accept Judy's anger without counterattacking. She could contain and interpret the feelings to help Judy understand and not feel threatened by them.

The enormity of Judy's need and rage emerged later in the therapy. She was able to verbalise her desire to get away from Therapist B, to hurt her and to smash her belongings. For the first time Judy was able to acknowledge that, her own possessiveness disturbed her.

\section{Essential structure}

The essential structure is the final level of phenomenological explication. Incorporating all the interviews, the description embodies the necessary and sufficient conditions, constituents and structural relations which constitute the phenomenon of processing a projective identification.

In the situation of processing a projective identification, the therapist comes to embody an incongruent, unfamiliar and inauthentic experience, aligned with the client's perception of the therapist. Discomfort prompts the therapist to bring to awareness and thematise the experience. 
The therapist initially tries to make sense of the experience purely in terms of their own world (external events or countertransference), without reference to the client. This process fails and the client is then included in attempted understandings. The therapist alternates between: 1) avoiding the experience, which results in conflict with the client and with therapeutic ideals; and 2) appropriating it, which gives rise to feelings of inauthenticity. The alternating between the two positions stops when the therapist realises that the experience is co-determined by the client and therapist.

From a position of reflective distance, the therapist re-appropriates aspects of their own existence unavailable to them while underthe influence of the client's projective identifications. These reclaimed aspects of self are then compared with the evoked experience thus differentiating the contributions of the therapist and the client.This process leads to greater clarity and understanding. Feeling relieved and lighter, the therapist experiences a renewed surge of enthusiasm to understand the process and work therapeutically with the client.

Temporarily the therapist "gives in" to the felt experience and the client's perception of them. The therapist feels less drawn to either disowning or appropriating the experience, and is able to remain simultaneously open to the therapist's own separate reality.

The client is later able to re-appropriate the warded off aspects of their existence, which had temporarily been embodied and later verbalised by the therapist.

\section{Discussion}

The therapist's experience of processing a client's projective identification, as explicated in this study, will now be discussed in relation to some pertinent aspects of theory. Clinical vignettes from the interviews are used to augment understanding.

\section{Thematising the therapist's felt experience}

The first step in processing a projective identification consists of the therapist's struggle to thematise and shape the felt experience into words. This has variously been described as the movement from pre-ontological to ontological (Gendlin,1978), from pre-reflective experience to the symbolic world of language and shared meanings (Ogden, 1985; Rey, 1986a), alpha elements to beta elements (Bion, 1957, 1959), and Type A to Type B communication (Langs, 1978). It was found that the recognition and articulation of the unthought known (Bollas, 1987) reduced the psychological strain experienced by the therapists.

The therapists in the study were present to a wide range of experiences they believed were projective identifications. Some examples are; Therapist A began to doubt his perception and memory and felt bewildered and confused. He felt and thought he had lost, or was excluded from something, but did not know what it was. The world became a terrifying place and he feared he was losing his sanity.

Therapist $\mathrm{C}$ felt negative towards his client and himself, and thought he was not helping sufficiently. He experienced loss, separation, anger, impotence, rejection, betrayal, hurt, depression and envy.

Therapist G felt sad, lonely, lost and abandoned. He felt disconnected from people, experienced the world as cold, desolate, and stripped of warmth.

The common denominator in the reported feelings was the discomfort and uneasiness evoked in the therapist. The therapists felt uneasy, incongruent and inauthentic. In a similar 
vein, feelings resulting from projective identifications have been described as foreign (Swartz-Salant, 1988), strange and uncommon (Grinberg, 1962), mysterious (Bion, 1962), and that the therapist feels shaken (Ogden, 1982) and puzzled by their over-reaction (Segal, 1981). This affirms Ogden's (1997) view that feelings resulting from projective identification are by their very nature "highly charged, painful, conflict-laden areas of human experience" and are difficult for both "the projector and the recipient to accept" (p.367).

The influence, or gravitational pull (Gorkin, 1987), of the client's projective identifications varied in strength and duration. Most of the therapists experienced the feeling state solely during the session. However, three therapists felt the influence of the experience outside the confines of the therapy room. Grinberg (1962) terms this the postponement of the effects of projective identification. He describes how the feelings may be displaced onto other situations.

Two characteristics of the experience assisted the therapist in bringing it to articulated awareness, vis-a-vis; a) unfamiliar to the therapist's everyday experience, and b) out of proportion to the lived situation in the session. This discrepancy, or poor fit, gave rise to feelings of discomfort and uneasiness, thereby calling the therapist to focus on the experience and bringing it to awareness. Pointing to the same latency, Parker (1985) shows how reflective awareness is borne out of discomfort and being ill-at-ease with others. $\mathrm{He}$ shows how this relationship between discomfort and awareness is described by Harding (1973) who says that "...consciousness arises only at the point of discomfort...conflict might be called the mother of awareness” (p.201).

This raises an important point. If the induced experience is congruent with the therapist's experience of themselves, no dissonance or uneasiness will arise and the experience will remain unthematised. The therapist's experience will remain frozen (Gendlin, 1978) at the pre-reflective level. It is postulated that the high rate of burnout amongst psychotherapists is partly due to unrecognised projective identifications that have insidiously taken hold of the therapist's world, highlighting the importance of clinical supervision and personal therapy.

\section{Initial avoidance of the experience}

The fear of the contained (Bion, 1962, 1977; Langs, 1976), psychic infection (Jung, 1946) and being driven crazy (Searles, 1979) initially induces the therapist to attempt to get rid of the experience. The therapist's inability to tolerate the adversary position may result in what Langs (1975) terms a therapeutic misalliance, which reduces the therapist's anxiety but results in the client's deterioration outside the therapeutic context. An example of this process follows:

Joan accused Therapist $\mathrm{C}$ of not helping her sufficiently, and not communicating as well as her previous therapist (who has left her by emigrating). She threatened to terminate. The therapist began to think that he was useless and not good enough. He felt lost, betrayed, hurt, impotent and envious. Therapist $\mathrm{C}$ did not feel at ease in the sessions and experienced the following feelings and fantasies; 1 ) a desire to try harder and give the client what she wanted, 2) A desire to kick her out coupled with the fantasy saying, "Get the bloody hell out of here. You don't think I am good enough, you think your previous therapist is better. Go to her. I will give you a ticket", 
3) In his own mind, he denigrated the previous therapist by criticising her for not dealing adequately with the separation, and for "giving too much to a borderline client with a frustration tolerance problem”. Therapist C began to feel uneasy and anxious because the strategies went counter to his therapeutic training and intent. Joan's bulimic symptoms reappeared and she threatened to leave therapy again. Retrospectively the therapist realised that these were all ways of avoiding the experience Joan was attempting to induce in him.

In summary, the avoidant strategies employed by the therapist give rise to conflict with the client and the therapist's training and therapeutic ideals. A vicious cycle of conflict develops in the therapeutic relationship. The more the therapist tries to avoid/transform the specific mode of being with the client, the more tenaciously the client relates in a way, which forces the therapist to appropriate that mode. Similarly, the more the client tries to relate to the therapist in this way, the more the therapist tries to relate in a way that avoids it.

\section{Realisation of the co-constituted nature of the experience and the movement towards understanding}

It was found that a vital turning point in the processing of a projective identification, is the therapist's realisation that their experience is co-constituted by the client. In the earlier stages of the process, the power and intensity of the experience invites the therapist to attempt to make some sense of it. This draws attention away from the client and the therapeutic process. The therapist first tries to make sense of the experience in terms of his or her own world (eigenwelt) and the world out there (umwelt). Therapist E described the process as follows:

I was deadened and could not hold the content of the session. My thoughts at the time were really about me. At that point I did not think that there was something going on with her. I was thinking of myself, "Why are you so tired? Did you have a late night? Is there enough air in the room? Is it from the afternoon sun pouring in"? It was as if I did not want to be involved at that point with what was going on with the client, but was thinking why I was so exhausted. So in struggling to keep myself awake and understand why I was so sleepy at that point, I was looking at what was going on in me.

When partially out of the grip of the experience, the therapist begins to realise the experience is similar to an un-appropriated aspect of the client's world. This prompts consideration of the possibility of the experience as the result of a projective identification.

The therapist's realisation that the feeling state is co-constituted by the client heralds a change in attitude towards their experience and the therapy. The feeling state loses some of its luminosity and hold on the therapist who then becomes more attuned to the client and the therapeutic process. The therapist becomes mobilised to understand rather than deny, disguise or disown the experience.

Therapist A described how his understanding of the co-constituted nature of the experience rescued him from the confusion and having to act out the feelings. The minute he began to think that the experience was not entirely his; he felt less need to challenge the 
client's statements about him and could work with them therapeutically.

One of the therapists described their experiences as follows:

When it started to become clear to me that it was a projective identification, suddenly it felt like a relief. It just suddenly started to click. There was this growing sense of relief that it (the process) was ok. A sense of relief and exciting challenge. The sense of - let's see what happens.

\section{Gaining reflective distance}

In personally characteristic ways, the therapist moves away from the induced experience, thereby creating psychological distance from the client. With a certain degree offreedom (Rey, $1986 \mathrm{a}, 1986 \mathrm{~b})$ the therapist is able to investigate the experience without being overwhelmed or drowning (Racker, 1957) in it.

Most of the therapists in the study could only reflect upon the therapeutic process after the session, out of the physical vicinity of the client. In the case of the more pernicious and powerful projections, the therapist needed the added strength, support and theoretical input from supervision and at times personal psychotherapy.

It was found that the techniques used to avoid the induced experience, although somewhat disruptive to the therapeutic process, also served to create some reflective distance between the therapist and the felt-experience.

\section{Differentiation}

The therapist's experience is co-constituted by the client and therapist, and as such is neither truly the therapist's nor the client's. By disowning the experience, the therapist not only gets rid of the projected aspect but also an aspect of self, thereby impoverishing the therapist's existence.

Complete appropriation of the experience, consisting of retaining the self-aspect and taking on aspects of the client's world, lead to feelings of inauthenticity for the therapist. An important aspect of processing the projective identification consists of the therapist alternating between these two styles.

The impasse is broken when the therapist is able to differentiate his or her own contribution from that of the client. One method of differentiation consists of the therapist comparing the experience in the session to a similar experience that has occurred while not under the influence of the client. For example, Therapist A compared his feeling of forgetfulness during the sessions, to the similar experience of losing his keys. He thought that in the ordinary experience of forgetting keys he knew that he had forgotten, that he had forgotten keys, and that there were such things as keys. He may be upset that he had forgotten due to his age, but was not terrified. However, with his client, he experienced panic and terror. He felt forgetful, but was not sure what he had forgotten or even if he had forgotten. The differentiation between the two experiences allowed the therapist to feel more sympathetic and understanding towards the client's experience, giving rise to an increase in rapport.

Once I understood that it was her memory lapse, I wanted to examine it further. Once I could accept that I also have memory lapses, but that they don't happen in that way 
- that mine are different and that we were dealing with her experience in the session, then I could accept it was allocated to me and not feel it as part of me. I could allow her to say that it was my forgetfulness.

\section{Re-appropriation of the therapist's own reality}

When under the influence of a projective identification the therapist is restricted to a narrow way of being, consistent with the client's experience of the therapist. Ogden (1983) describes how the client induces this through interpersonal pressure and by selectively excluding aspects of the therapist's personality that do not correspond to the features of the projective identification. The therapist becomes closed to other aspects of their personality, especially those which may contradict the invoked experience. An important aspect of processing the projective identification consists of the therapist re-appropriating those aspects of experience to which they had become closed, and then considering them in relation to feelings induced by the client.

Therapist G described how he concretely re-appropriated aspects of his everyday world. For a few hours after each session with his client David he felt that the world was cold, desolate, grey and stripped of warmth. He felt isolated from people and had no access to his own warm memories. After each session with David, the last one of the day, he would go home and try to regain his warm memories and sense of okayness. He would create a warm, at-home feeling by switching on the lights, playing some music and preparing a meal. The sense of returning home and being filled up by the warm food, music and light, helped rekindle Therapist G's own warm memories.

This research indicates that the therapist is only able to be fully present to the experience after re-appropriating those aspects of their world, which had become inaccessible whilst under the influence of the projective identification. The re-appropriation puts the therapist in touch with their everyday world, thereby reducing some of the confusion and anxiety over what sort of person they really are and what sort of person the client thinks they are.

\section{Containment}

The therapist reaches a stage of openness to the invoked experience (projective identification) and is able to treat the client's perceptions as true, irrespective of the therapist's belief regarding their validity. Containment in this sense implies that the therapist is able to live the experience without feeling excessively drawn to either disowning it, thereby feeling impoverished, or owning it and feeling inauthentic. The therapist no longer feels drawn to questioning the validity of the client's perception, but rather accepts it as the client's reality. At the same time, however, the therapist is able to remain in touch with his or her own authentic existence.

For example, Richard would condemn and rail against Therapist D, accusing her of being a bad therapist. The therapist felt attacked and could not contain the feelings that were evoked in her. The explication of the protocol highlighted three factors that helped her contain the feelings, allowing her to work with, rather than defensively challenge the perception; 1) she realised that people think differently and that there is no absolute truth, 2) she realised she would survive regardless of what the client felt about her, and 3) she understood that therapeutically Richard needed to set her up as a mother figure he could berate for her neglect. 
Therapist D. explained her progression from warding off to containing the client's feelings as follows:

(The client's belief) ... was true for him. But it was only at the point at which I understood that he needed it to be true, that I could let it be true. And it started to lose its amazing significance and stopped being such an issue for me. I can [now] acknowledge that in reality I have actually been a bad therapist at times, and in reality I have actually been a good therapist at times. But the question of whether I am good or bad, just does not somehow seem to be that important, and that his experiencing me as a bad therapist, whether that is true or false is not important any more, whereas before that it seemed to be the crucial thing - that I had to defend myself against. Now it does not seem to be important. It is almost as if I was being used, and I am still being used, and that is ok. He is needing to make me into something and the question of whether it is true or not is not the issue any more. I suppose what happened was the sudden realisation that he thought I was bad and that was true, but I don't think I am bad and that is also true. And it can just be like that.

This passage illustrates that the containment of a projective identification is neither a rejection, nor an unqualified acceptance of the invoked experience. The therapist does not question whether the invoked feelings are true or false, real or unreal, but moves beyond the either/or position and works with the feelings as if they were real. This resonates with Ogden's $(1979,1982)$ contention that what the client is presenting must be treated by the therapist as a type of transitional phenomenon (Ogden, 1985; Winnicott, 1953), wherein the question of whether the client's truth is reality or fantasy is never an issue. As with transitional phenomenon, it is both reality and fantasy, subjective and objective.

Following Winnicott (1953), the therapist needs to accept, and not question, the paradox that the client's perception is correct and incorrect at the same time.

\section{Using feeling as understanding}

The lived experience of embodying a disowned aspect of the client's existence permits the therapist to be present to, and gain a deep understanding of that existence. More than mere intellectual understanding, the directness and immediacy of a projective identification brings the client's world to life for the therapist. The impact is captured by Wieland-Burston's $(1987)$ statement that the client "...puts his mark in the clay of my being. And this mark leaves an impression, an imprint on me. It touches me” (p.124).

In the present research, the therapists reported that through the invoked experiences, they had achieved levels of empathy and understanding of the client's world, that would not otherwise have been possible. They also spoke of how their awareness around similar themes had deepened and at times changed. Highlighting a similar point, Ogden (1983) states that:

This identification on the part of the therapist represents a form of understanding of the patient that can be acquired in no other way. In my opinion, it is not possible to analyse the transference without making oneself available to participate to some degree in this form of identification (p. 236). 


\section{The client's re-appropriation of disowned aspects}

The final stage of processing a projective identification occurs when the client appropriates aspects of their existence that had temporarily been embodied and thematised by the therapist. The client is able to thematise, verbalise and take up the possibilities of that disowned aspect of existence. Two short examples follow:

Richard moved away from his excessive need for external achievement and owned some of his neediness and the pain involved in the struggle to obtain warmth from people. Being able to rail at his therapist opened the way to being able to rail against his mother in the therapy. For the first time in his life Richard felt his rage at his mother for being in the way and preventing him from having a real father-son relationship.

Judy re-owned and was able to verbalise her excessive dependency and need for her therapist, as well as her rage at her therapist's separateness.

\section{Conclusion}

A successful cycle of projective identification is conceptualised as consisting of; 1) the client's unconscious phantasy of projecting split-off parts or affects into the therapist, 2) the client's simultaneous interpersonal pressure on the therapist to play out a role congruent with the phantasy, 3) the therapist's processing of the evoked feelings, and finally, 4) the reintrojection of the projection in modified and less pernicious form by the client through interaction with the therapist.

Using the phenomenological method, this study aimed to explicate the third phase, i.e., the therapist's experience of processing the projective identification. In summary, this process takes the following form: Discomfort prompts the therapist to bring the experience to conscious awareness; initial attempts at understanding focus on environmental and personal (countertransferential) issues; once the therapist realises the interactional nature of the experience, they include the client in explanatory attempts.

The therapist alternates between; a) avoiding the experience, which conflicts with the client and therapeutic ideals, and b) appropriating the experience, which feels inauthentic.

From a position of reflective distance, the therapist re-appropriates aspects of their own existence closed to the under the influence of the client's projective identification. These aspects are compared with the evoked experience thus differentiating the therapist and client's contributions.

The therapist considers their personal contributions (countertransference) to the experience and how these link with conflicted aspects of their own existence. The therapist then integrates these denied aspects with the larger healthier aspects of their own personality.

The therapist feels relieved and lighter, and experiences a renewed desire to understand the experience and work with the client. The therapist gives over to the experience without feeling drawn to disowning or appropriating it. The therapist treats it as a transitional phenomenon, not questioning the truth or ownership. During this time the therapist learns from the experience and consolidates their theoretical understanding. 


\section{MARK THORPE}

The client is later able to appropriate the disowned aspects of their own world that had temporarily been projected into, and embodied and verbalised (interpreted) by the therapist.

\section{References}

Adler, G., \& Rhine, M.W. (1988). The selfobject function of projective identification. Curative factors in psychotherapy. Bulletin of the Menninger Clinic, 52(6), 473-491.

Bion, W. R. (1957). Differentiation of the psychotic from the non-psychotic personality. International Journal of Psychyo-Analysis, 38, 266-275.

Bion, W. R. (1959). Attacks on linking. International Journal Psychoanalysis, 40, 308-315.

Bion, W. R. (1961). Experience in groups. London, United Kingdom: Tavistock.

Bion, W. R. (1962). Learning from experience. London, United Kingdom: Heinemann.

Bion, W. R. (1977). Seven servants. New York, NY: Jason Aronson.

Bollas, C. (1987). The shadow of the object: Psychoanalysis of the unthought known. London, United Kingdom: Free Association Books.

Epstein, L., \& Feiner, A. H. (1979). Countertransference. New York, NY: Jason Aronson.

Gendlin, E. T. (1978). Befindlichkeit: Heidegger and the philosophy of psychology. Review of Existential Psychology and Psychiatry, 16, 43-71.

Giorgi, A. (1970). Psychology as a human science: A phenomenologically based approach. London, United Kingdom: Harper \& Row.

Giorgi, A. (2009). The descriptive phenomenological method in psychology: A modified Husserlian approach. Pittsburgh, PA: Duquesne University Press.

Giorgi, A., \& Giorgi, B. (Eds.). (2008). Phenomenology. London, United Kingdom: Sage.

Gold, S. (1983). Projective identification: The container and reverie as concepts in applied psychoanalysis. British Journal of Medical Psychology, 56, 279-285.

Gorkin, M. (1987). The uses of countertransference. London, United Kingdom: Jason Aronson.

Grinberg, L. (1962). On a specific aspect of countertransference due to the client's projective identification. International Journal of Psychoanalysis, 43, 436-440.

Grotstein, J. S. (1981). Splitting and projective identification: Jason Aronson.

Harding, M. E. (1973). Psychic energy: its source and its transformation. Princeton, NJ: Princeton University Press.

Holloway, I., \& Todres, L. (2003). The status of method: Flexibility, consistency and coherence. Qualitative Research,3(3), 345-357. doi:10.1177/1468794103033004

Jung, C. G. (1946). The psychology of the transference. In H. Read, M. Fordham, \& G. Adler (Eds.), The collected works of C.G. Jung (Vol.16). Princeton, NJ: Princeton University Press.

Kernberg, O. F. (1987). Projection and projective identification: Developmental and clinical aspects. Journal of the American Psychoanalytic Association, 35(4), 795-820.

Klein, M. (1946). Notes on some schizoid mechanisms. International Journal of Psychoanalysis, 27, 99-110.

Kruger, D. (1985). Existential phenomenological psychotherapy and phenomenological research in psychology. In P. D. Ashworth, A. Giorgi, \& A. J. J. de Koning (Eds.), Qualitiative research in psychology. Pittsburg, PV: Pittsburg University Press.

Langs, R. (1975). Therapeutic misalliances. International Journal of Psychoanalytic Psychotherapy, 4, 77-105. 
Langs, R. (1976). The bipersonal field. New York, NY: Jason Aronson.

Langs, R. (1978). The listening process. New York, NY: Jason Aronson.

Langs, R. (1981). Classics in psychoanalytic technique. New York, NY: Jason Aronson.

Langs, R. (1982). Countertransference and the process of cure. In S. Slipp (Ed.), Curative factors in dynamic psychotherapy (pp. 127-152). New York, NY: McGraw-Hill.

Meissner, W. W. (1987). Projection and projective identification. Madison, CT: International Universities Press.

Ogden, T. H. (1979). On projective identification. International Journal of Psychoanalysis, 45, 317-333.

Ogden, T. H. (1982). Projective identification and psychotherapeutic technique. New York, NY: Jason Aronson.

Ogden, T. H. (1983). The concept of internal object relations. International Journal of Psychoanalysis, 64, 227-241

Ogden, T. H. (1985). On potential space. The International Journal of Psychoanalysis, 66, 129-141.

Ogden, T. H. (1997). Reverie and interpretation: Henry James (1884). The Psychoanalytic Quarterly, $66,567-595$.

Ogden, T. H. (2016). Reclaiming unlived life: Experiences in Psychoanalysis. London, United Kingdom: The New Library of Psychoanalysis.

Parker, M. A. (1985). An empirical phenomenological study of the psychological manifestations of ontic conscience as derived from Heidegger's ontological conception of that phenomenon [Unpublished Masters dissertation]. Rhodes University, Grahamstown, South Africa.

Racker, H. (1957). The meanings and used of countertransference. Psychoanalytic Quarterly, 26, 303-357.

Rey, H. (1986a). The psychodynamics of psychoanalytic and psycholinguistic structures. Journal of the Melanie Klein Society, 4, 73-92.

Rey, H. (1986b). Psycholinguistics, object relations theory and the therapeutic process. Journal of the Melanie Klein Society, 4, 53-72.

Rosenfeld, H. (1983). Primitive object relations and mechanisms. International Journal of Psychoanalysis, 64, 261-267.

Sandler, J. (1976). Countertransference and role-responsiveness. International Review of Psychoanalysis, 3, 43-48.

Sandler, J. (1987). The concept of projective identification. Madison, CT: International Universities Press.

Searles, H. F. (1979). Countertransference and related subjects: Selected papers. New York, NY: International Universities Press,.

Segal, H. (1981). The work of Hanna Segal: A Lleinian approach to clinical practice. New York, NY: Jason Aronson.

Spillius, E., \& O'Shaughnessy, E. (2012). Projective identification: The fate of a concept. London, United Kingdom: Routledge.

Wertz, F. J. (1983). From everyday to psychological description: Analysing the moments of a qualitative data analysis. Journal of Phenomenological Psychology, 14(2), 197-241.

Wertz, F. J. (1986). Common methodological fundaments of the analytic procedures in phenomenological and psychoanalytic research. Psychoanalysis and Contemporary Thought, 9 , 563-603.

Wieland-Burston, J. (1987). When the doodling stops or the analyst and his/her health. Free 
Associations, 8, 115-131.

Winnicott, D. W. (1953). Transitional objects and transitional phenomena. International Journal of Psychoanalysis, 34, 89-97.

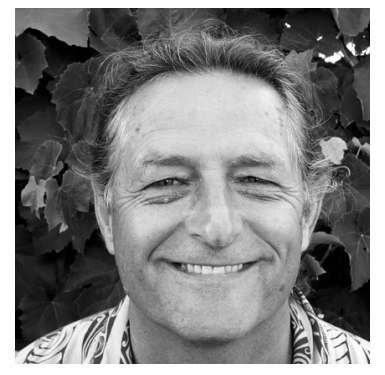

Dr Mark Thorpe is a senior lecturer at Auckland University of Technology and practices as a clinical psychologist at Psychotherapy at Apollo. He trained in a variety of therapeutic modalities and worked in private, governmental, and university settings in South Africa and Aotearoa New Zealand. Mark is Chair of Training for the New Zealand Institute of Psychoanalytic Psychotherapy, and a member of the Psychoanalytic Psychotherapy Association of Australasia and the International Association of Relational Psychotherapy and Psychoanalysis. He has held the positions of Vice President of the South African Institute of Psychotherapy, Chairperson of the Cape Town Psychoanalytic Society, Psychology Professional Advisor for Pacific Health DHB, Committee Member of the NZ Institute of Counselling Psychology, and Head of Psychology at Auckland University of Technology. Contact details: mark.thorpe@aut.ac.nz . 